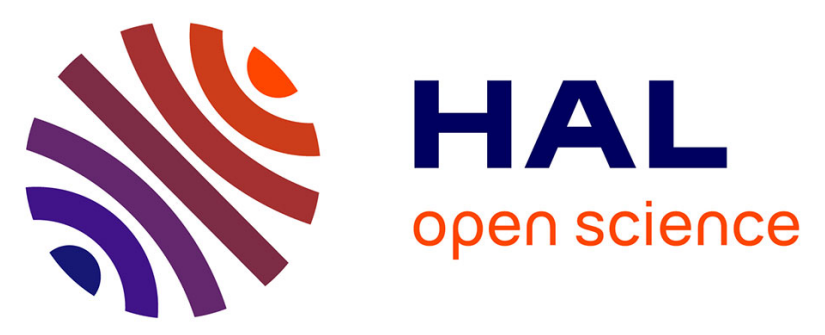

\title{
A model for community representation and participation in HIV prevention trials among women who engage in transactional sex in Africa
}

Charles Shagi, Andrew Vallely, Stella Kasindi, Betty Chiduo, Nicola Desmond, Selephina Soteli, Natujwa Kavit, Lisa Vallely, Shelley Lees, Richard Hayes, et al.

\section{To cite this version:}

Charles Shagi, Andrew Vallely, Stella Kasindi, Betty Chiduo, Nicola Desmond, et al.. A model for community representation and participation in HIV prevention trials among women who engage in transactional sex in Africa. AIDS Care, 2008, 20 (09), pp.1039-1049. 10.1080/09540120701842803 . hal-00513443

\section{HAL Id: hal-00513443 \\ https://hal.science/hal-00513443}

Submitted on 1 Sep 2010

HAL is a multi-disciplinary open access archive for the deposit and dissemination of scientific research documents, whether they are published or not. The documents may come from teaching and research institutions in France or abroad, or from public or private research centers.
L'archive ouverte pluridisciplinaire HAL, est destinée au dépôt et à la diffusion de documents scientifiques de niveau recherche, publiés ou non, émanant des établissements d'enseignement et de recherche français ou étrangers, des laboratoires publics ou privés. 

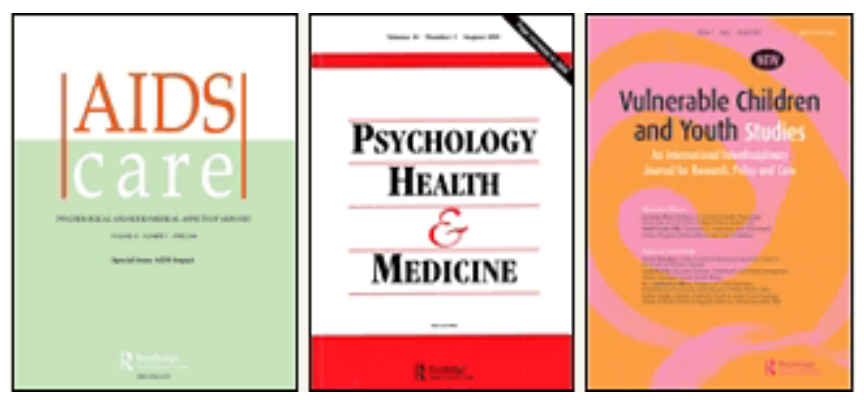

\section{A model for community representation and participation in HIV prevention trials among women who engage in transactional sex in Africa}

\begin{tabular}{|r|l|}
\hline Journal: & $\begin{array}{l}\text { AIDS Care - Psychology, Health \& Medicine - Vulnerable Children } \\
\text { and Youth Studies }\end{array}$ \\
\hline Manuscript ID: & AC-2007-06-0256.R2 \\
\hline Journal Selection: & AIDS Care \\
\hline Keywords: & community, participatory research, microbicide, clinical trial \\
\hline
\end{tabular}

\section{scholarONE" \\ Manuscript Central}


Title: A model for community representation and participation in HIV prevention trials among women who engage in transactional sex in Africa 


\section{ABSTRACT}

Actively engaging communities in effective partnerships for the design and implementation of HIV prevention research is vital to the successful conduct of ethically robust, locally-appropriate clinical trials in developing countries. This is especially true in vulnerable at-risk sub-populations, where definitions of 'community', 'participation' and 'representation' can be difficult to apply. This study was conducted to investigate the feasibility of a participatory model of community liaison among an occupational cohort of women at high-risk of HIV and sexually-transmitted infections (STIs) in Mwanza City, northwest Tanzania in preparation for a phase III vaginal microbicide trial. This approach was rooted in participatory action-orientated research (PAR) and used tools adapted from participatory learning and action (PLA) techniques. During the feasibility study, a mobile community-based sexual and reproductive health service for women working as informal food vendors or in traditional and modern bars, restaurants, hotels and guesthouses was established in 10 city wards. Participatory mapping was carried out by project fieldworkers and wards divided into 78 geographical clusters of facilities in consultation with community members and study participants. Representatives at cluster and ward level were elected in a process facilitated by the site Community Liaison Officer $\underline{(\mathrm{CLO})}$ and a site-level Community Advisory Committee $\underline{(\mathrm{CAC})}$ established. A logical framework was used to guide the implementation, monitoring and evaluation of the community liaison system (CLS) within the broader feasibility study. The CLS was essential to the successful conduct of the feasibility study and has now been consolidated and expanded as part of the on-going MDP301 phase III microbicide trial in Mwanza. The participatory model presented in this paper is likely to be generalisable to other vulnerable, stigmatised, at-risk study populations in resource-limited settings.

Abstract word count: 275

KEYWORDS: community, participatory research, microbicide, clinical trial

Deleted: Objectives: To investigate the feasibility of a participatory mod

of community liaison among an occupational cohort of women at high-risk of HIV and sexually-

transmitted infections in Mwanza City northern Tanzania in preparation for a phase III vaginal microbicide trial. 9 Methods: Participatory actionorientated research methods were used to develop locally-appropriate community liaison systems. 1 Results: A

Formatted: Font: Not Bold

Deleted: ('facilities') has been

Deleted: out in each ward

Deleted: .

Deleted: W

Deleted: were

\begin{tabular}{l} 
Deleted: Interaction between study \\
participants and community \\
representatives was high: $77 \%$ of \\
women interviewed knew their cluster \\
representative and had interacted \\
with her at least once in the past to \\
discuss a project-related concern. \\
Conclusions: This paper presents a \\
community-led participatory model for \\
community liaison in HIV prevention \\
trials among women who engage in \\
transactional and commercial sex in \\
Tanzania that is likely to be \\
generalisable to other vulnerable, \\
stigmatised, at-risk study populations \\
in resource limited settings. \\
\hline Deleted: 15 \\
\hline
\end{tabular}




\section{INTRODUCTION}

Participatory techniques such as rapid rural appraisal (RRA), participatory rural appraisal (PRA) and participatory learning and action (PLA) have been used in developing countries since the 1980 's in the design and implementation of locally-appropriate community-based interventions (Chambers, 1983, 1997). These approaches typically employ a combination of diagramming and visualisation techniques, such as transect walks, seasonal calendars, community mapping, chapatti diagrams, scoring and pair-wise matrices, to facilitate community-led dialogue between community members, local stakeholders and community development workers (Busza \& Schunter, 2001; Chambers, 1997; Mahr, Wuestefeld, ten Haaf, \& Krawinkel, 2004; Muruli, Reardon Kisuya Muthui \& Vallely 2001). Allied techniques include agro-ecosystems research (Chambers, 1997); rapid ethnographic assessment (NIMH, 2007); participatory action research (Baum, MacDougall, \& Smith, 2006; Cornwall \& Jewkes, 1995; Khanlou \& Peter, 2005); and rapid participatory appraisal (Annett \& Rifkin, 1995; Brown, Lloyd, \& Murray, 2006; Murray, 1999;

Vallely, Scott, \& Hallums, 1999).

The development and widespread application of these techniques has largely been driven by an appreciation among development workers, researchers and community stakeholders of the limitations of 'traditional' approaches to community-based research in which surveys are administered by outsiders with limited community involvement during the research design, data interpretation or project implementation phases (Chambers, 1997; Ong, Humphris, Annett, \& Rifkin, 1991; Wright \& Walley, 1998). The use of participatory research techniques to facilitate effective partnerships between communities and researchers remains in its infancy however in the context of large-scale randomised-controlled clinical trials (Vallely, Shagi et al., 2007). Community Advisory Boards (CABs) are now a standard requirement in this setting and considered key to Good Participatory Practice in the conduct of HIV prevention trials (UNAIDS, 2007). CABs have been used in a variety of research and development settings to represent the views of local communities, promote joint working practices and to ensure effective, open dialogue between 
community members, researchers and project managers (Corcega, 1992; Cox, Rouff, Svendsen, Markowitz, \& Abrams, 1998; Macaulay \& Nutting, 2006). Morin et al (2003) in their review of CABs at six clinical research sites participating in the HIV Prevention Trials Network (HPTN), describe two principal CAB models: a 'broad community model' with representation from the wider community and a 'population-specific model' with representation from a specific target group, which typically includes actual or potential trial participants (Morin, Maiorana, Koester, Sheon, \& Richards, 2003). They pose three key questions for researchers planning HIV prevention trials: How is 'community' defined and by whom? Who speaks for this community i.e. how is representation determined? What role should community representatives play in the research process (e.g. protocol review, ethical considerations)?

The development of candidate vaginal microbicides and vaccines for HIV prevention has brought new challenges for researchers and communities because in many countries, phase III efficacy and safety trials are possible only among sub-populations known to be at increased risk of HIV infection, where HIV incidence rates are sufficiently high to make prevention trials feasible (Esparza \& Burke, 2001; Suligoi, Wagner, Ciccozzi, \& Rezza, 2005). These include female sex workers (Page-Shafer et al., 2005); prisoners (Moser et al., 2004); intravenous drug users (Meyers et al., 1995); the homeless (Nyamathi,et al.,2004); and men that have sex with men (Sherr, Bolding, \& Elford, 2004). In many resource-limited settings, such populations are often marginalised within the broader community and considered vulnerable both in terms of increased risk of HIV and sexually transmitted infections (STIs), and due to stigma, poverty, social exclusion and lack of access to education, health care and other essential services (Gysels, Pool, \& Nnalusiba, 2002; Mills et al., 2006). Traditional concepts of 'community', 'participation' and 'representation' can be difficult to apply in such environments (Busza \& Schunter, 2001; Vallely, Shagi et al., 2007). In order to ensure that effective, representative and participatory community liaison systems are developed, and to avoid misunderstandings and distrust developing between potential participants and external researchers, it is vital that researchers and local stakeholders develop and jointly agree robust locally-relevant definitions of what constitutes 'community' in a

Page 4 of 20 
specific setting (MacQueen et al., 2001; Nyamathi et al., 2004). This paper describes how an approach rooted in participatory action research (Baum et al., 2006) enabled effective, representative systems for community liaison to be developed during the Microbicide Development Programme's (MDP) microbicide feasibility study in Mwanza became the foundation for community liaison during the on-going MDP301 phase III clinical trial.

Deleted: City

Deleted: north-western

Deleted: then

Deleted: in Mwanza

We believe this community-led participatory approach represents a useful model for community

liaison in HIV prevention trials among other vulnerable, at-risk cohorts in sub-Saharan Africa.

Deleted: conducted

\section{The Microbicide Development Programme}

Mwanza is one of six centres in sub-Saharan Africa participating in the Microbicides Development Programme (MDP), an international partnership for the development of vaginal microbicides for HIV prevention(MDP, 2007). During a feasibility study in preparation for the MDP301 phase III efficacy and safety trial of the candidate vaginal microbicide PRO2000/5, a community liaison system was established at the MDP Mwanza site, located in the Lake Victoria region of northwest Tanzania. Key objectives were to investigate the feasibility of a participatory model of community liaison in this context, using tools adapted from participatory learning and action (PLA) techniques; to establish locally-appropriate mechanisms of representation for women participating in the feasibility study; and to build a robust system capable of identifying and responding to key projectrelated concerns among participants and the broader community.

The feasibility study was conducted among women working in food and recreational facilities in ten administrative wards in Mwanza City (Vallely, Kasindi et al., 2007). Some women in this occupational group are known to periodically supplement their income through transactional sex and although not necessarily perceived as commercial sex workers within the broader community (Boerma et al., 2002; Clift et al., 2003; Desmond et al., 2005b; Mgalla \& Pool, 1997), are nonetheless at increased risk of STIs and HIV infection (Kapiga, Sam, \& Shao, 2002; Nkya, Gillespie, \& Howlett, 1991; Vallely, Kasindi et al., 2007). Weekly community-based clinics were established at, selected guesthouses in each city ward. Free reproductive health services,
Deleted: $S$

Deleted: ,

Deleted: funded by the UK Department for International Development and Medical Research

Council (MRC), and coordinated by

the MRC Clinical Trials Unit and

Imperial College, London

Deleted: facilitated by the use of

Deleted: effective

Deleted: १

Deleted: community-based reproductive health

Deleted: by the project

Deleted: within 
including STI syndromic management, family planning, health education, and voluntary HIV counselling and testing (VCT) were provided, as previously described (Vallely, Kasindi et al., 2007).

Deleted: I

Deleted: १

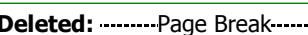

\section{METHODS}

\section{Participatory mapping}

Project fieldworkers carried out a participatory mapping exercise in June 2002 in which food and

recreational facilities ('facilities') in ten wards in Mwanza City were identified and mapped by hand. Deleted: onto pieces of paper

Two fieldworkers spent an average of four weeks in each ward familiarising themselves with the local environment, walking between facilities and introducing themselves and the project to local community leaders and stakeholders, Local community members such as ward officials, facility owners and managers actively participated in this process, walking with the research team to help identify facilities; jntroducing fieldworkers to owners, managers and staff at new facilities; and by reviewing the accuracy of draft ward maps jn the field. Local landmarks, roads, waterways and other features were also identified by community members and recorded on ward maps. Each facility was identified by name and type, according to predetermined criteria developed by the project and community stakeholders and the suitability of potential guesthouse for communitybased reproductive health clinics jointly agreed. For example, some facilities were considered unsuitable clinic sites due to their relatively inaccessible location within the ward or due to their 'reputation' of being associated with commercial sex work within the local community. Following a pilot study in Mirongo ward in July 2002, weekly clinics were established within selected guesthouses in ten wards by October 2002

\section{Situational Analysis}

To investigate pre-existing community networks and the views of local stakeholders as to how a community liaison system for women participating in the feasibility study might best be developed,
Deleted: as they went

\begin{tabular}{l} 
Deleted: by \\
Deleted: by \\
Deleted: as they were developed \\
\hline $\begin{array}{l}\text { Deleted: who assisted fieldworkers } \\
\text { to }\end{array}$ \\
\hline Deleted: these \\
\hline Deleted: to \\
Deleted: following discussion with \\
ward officials, facility workers, owners \\
and managers. \\
Deleted: T \\
\hline Deleted: and hotel sites \\
\hline $\begin{array}{l}\text { Deleted: were also discussed with } \\
\text { community stakeholders, in particular } \\
\text { potential study participants, and a } \\
\text { number of possible sites visited in } \\
\text { each ward. }\end{array}$ \\
\hline $\begin{array}{l}\text { Deleted: short } \\
\text { Deleted: community-based } \\
\text { reproductive health }\end{array}$ \\
Deleted: city \\
\hline
\end{tabular}


a situational analysis was carried out in April 2003 by two senior members of the research team. More than 20 local stakeholders were interviewed using a simple open-ended key informants' guide including potential study participants, facility owners and managers, city and ward-level health officers and administrative staff, representatives of local non-government and communitybased organizations (NGOs, CBOs), project clinical and social science staff and community members such as balosi (groups of approximately ten households) leaders.

\section{Involving local stakeholders in the design of the community liaison system}

Following the situational analysis, the project Community Liaison Officer (CLO; CS), a senior member of the Mwanza research team with over 15 years experience of community development in Tanzania, coordinated a series of participatory community workshops in June-July 2003 with study participants, facility workers, owners, managers and project fieldworkers at facilities in three study wards (Igoma, Nyamagana, Mkuyuni). These workshops used tools adapted from participatory learning and action (PLA) techniques such as listing, ranking and pair wise matrices to help workshop participants develop and convey locally-relevant definitions of 'community' to the research team. The workshops culminated in a preliminary model for community liaison in the context of the Mwanza feasibility study. A successful community liaison pilot study was conducted in the same three wards in August 2003 following which the model was rolled out to all ten study wards over the next 12 months.

\section{Monitoring and evaluation}

A simple logical framework (Nancholas, 1998) was developed by the community, clinical and social science teams to document and define key objectives of the community liaison system (CLS), to ensure that activities remained focussed and linked to key measurable outcomes, and to promote a rigorous monitoring and evaluation framework (Figure 1). The overarching purpose of the CLS, as defined within the logical framework, was 'to improve the participation of women and community support for the project'. In this context, 'participation' was seen as a process of effective, open dialogue and partnership working between the community and the research team

Page 7 of 20 
in order to develop shared understanding of research objectives and joint action plans on the most acceptable and appropriate options for project implementation. Progress against enrolment and follow-up targets were used as indicators at purpose level since we believed that without effective community liaison, it would not be possible to meet broader feasibility study objectives. Other important factors felt likely to impact on recruitment and retention included participants' perceptions of the quality of clinic services, including staff attitudes; and their experiences of stigma and social harm related to study participation. A key role of the CLS was to provide a mechanism for capturing such concerns and perceptions and feeding these back to the research

management team to inform project implementation. This process has previously been reported in Deleted: in order detail (Vallely, Shagi et al., 2007).

A sub-study was conducted in July 2004 among 85 study participants from 20 randomly selected facility clusters to assess community representation in terms of the level and nature of interaction between study participants and their community representatives and specifically, investigated whether community representatives were actually known by other study participants, and how often participants were in touch with their representatives about study-related issues. A formal CLS evaluation based on an 'output-to-purpose' type project review was conducted in December 2004 (MDP-Mwanza, 2004).

\section{Ethics}

Ethical clearance for this research was obtained from the National Medical Research Coordinating Committee in Tanzania and the Ethics Committee of the London School of Hygiene and Tropical Medicine in UK. A trained nurse interviewer provided detailed information about the study to women at their first clinic visit. Written informed consent was obtained from all participants prior to enrolment.

<Figure 1 to be inserted around here>

Page 8 of 20 


\section{RESULTS}

\section{Lack of pre-existing structures for representation}

The situational analysis and participatory mapping identified few pre-existing structures able to Deleted: very represent the views or collective interests of women in this occupational group. The complexities, barriers and constraints to developing representative, participatory systems for community liaison in this setting were highlighted during the situational analysis but disappointingly, no clear consensus emerged as to potential models that might be piloted, In some areas, women working as informal food vendors in makeshift temporary structures (known locally as mamalishe) had formed organizations equivalent to trade unions, for example in the Mwaloni area adjacent to the international fish market in Kirumba. However, such organizations did not exist for mamalishe Deleted: ward working in any other areas of the city and none were identified for women working in other types of facilities. Established community structures such as the balosi (groups of approximately ten houses) were also felt to be inappropriate units of representation for women in the Mwanza cohort for several reasons. Typically, balosi do not include bars, hotels or similar facilities and hence represent a somewhat different 'community' to the one from which study participants were drawn. It was thought likely that women would fear disclosure, either of their participation in the study or their HIV status, should a system based on the balosi structure be developed and that this might increase their risk of social harm and stigmatisation. Finally, around three quarters of balosi leaders are men and therefore unlikely to be approached by female study participants, particularly those wishing to raise issues around clinical research procedures such as the need for frequent speculum examinations.

\section{Definitions of 'community' in the Mwanza feasibility study}

A fundamental problem in the early stages of the CLS in Mwanza was how to define 'community' in this setting. The research team considered that in the absence of a clear and robust definition, it would not be possible to develop locally-appropriate mechanisms for effective community representation and participation. Following the inconclusive results of the situational analysis, 
these issues were explored in participatory community meetings with potential study participants and local stakeholders as described above. Women working in food and recreational facilities who participated in the workshops expressed an allegiance with others in this occupational group due to shared experiences, perspectives, expectations and social networks. This construct of 'community' based on an occupational group also fitted closely with pre-determined eligibility criteria for participation in the Mwanza microbicide feasibility study (e.g. actively working in a food or recreational facility at the time of study entry; sexually active; over 16 years of age). A working definition of community as 'any woman who is currently working or has recently worked as a mamalishe or in a restaurant, guesthouse, hotel, grocery, traditional or modern bar' was therefore adopted by the research team and local stakeholders.

\section{A model based on geographical facility clusters}

Early in the development of the CLS in Mwanza it was noted that different types of facilities tend to cluster together naturally within each ward and that it was possible to define geographical clusters of facilities using ward maps. Mamalishe facilities and traditional bars (vilabu) selling locallybrewed beer tend to be situated in close proximity, typically in the more economically deprived areas of each ward (Figure 2). Modern bars, guesthouses, groceries, hotels and restaurants tend to be located in relatively more affluent areas (Figure 3). There also appeared to be distinct differences in the demographic and sexual behaviour characteristics and HIV/STI risk profile between women working in these different clusters (Vallely, Kasindi et al., 2007), which raised concerns about their ability to interact with or represent each other that were confirmed by facility workers attending community workshops. Facility workers also felt that the way in which women dress was important and reflected broader socio-demographic differences between facility types.

From these observations grew an idea that facilities could be grouped together into two distinct cluster types: type-A (mamalishe / kilabu) and type-B (bars, hotels, restaurants, guesthouses, other; Figure 4).

<Figures 2 - 4 to be inserted around here> 
Through the community workshops, the project CLO, fieldworkers, facility workers, managers and owners agreed on a cluster-based CLS, the composition and location of each cluster, which were then drawn onto individual ward maps (Figure 5). Furthermore, facility workers suggested how their community should be represented and by whom. Suitable levels of representation (cluster, ward, city) were defined and a series of eligibility criteria agreed for representatives, including that they must be currently enrolled in the feasibility study or have participated in the past; be Deleted: community Deleted: representatives trustworthy, honest, approachable, kind and sympathetic; willing to undertake the role on a voluntary, non-monetary basis; able to act as an effective community advocate by recording issues and communicating concerns to the research team; and be well-known to women and easily located within the cluster. Workshop participants also suggested that community representatives be able to stand down or rotate periodically should they so wish (e.g. due to family or work commitments) and procedures for the identification and election of new representatives were agreed.

<Figure 5 to be inserted around here>

By July 2004, 78 facility clusters in ten city wards had been established, each with an elected representative. These clusters comprised a total of 344 facilities from which 1418 or $90 \%$ of the 1573 women participating in the feasibility study had been enrolled, with an average of 4.4 . facilities per cluster (MDP-Mwanza, 2004). It should be noted however, that at this stage the CLS did not cover all of the estimated 1107 facilities in the ten study wards but had largely developed around those facilities from which study participants had been enrolled. In addition, high mobility and early losses to follow-up within the cohort (Vallely, Kasindi et al., 2007) mean that the true level of representation was likely to have been considerably lower than the $90 \%$ estimate above. Minor disagreements regarding representation, selection procedures, cluster boundaries and the inclusion or exclusion of certain facilities were resolved by the project CLO and fieldworkers through cluster meetings. One of the 79 clusters originally established was closed following a citywide 'clean up campaign' by the City Council in early 2004 that resulted in the demolition and 
closure of facilities within this cluster. The campaign had its greatest impact on mamalishe, with many having to move from their existing places of work to areas with less suitable business opportunities e.g. relocations from the Kamanga ferry port area. Many women were forced to operate illegally, preparing food at home and carrying it to the areas where they previously worked, serving and selling the food direct from baskets. The campaign had less impact on

women working in permanent facilities such as bars, restaurants, guesthouses and hotels.

Ward and site-level representation were subsequently established by further rounds of community-led elections, facilitated by the site CLO, so that by December 2004, a site-level Community Advisory Committee (CAC) with 18 representatives from all the ten study wards had been established.

\section{Representation and interaction}

A key process indicator of representation was the sustainability of community meetings at all levels within the system (Figure 1). By December 2004, 95\% of cluster representatives were attending each quarterly ward-level meeting. Issues raised at monthly cluster-level meetings and recorded by cluster representatives in notebooks were further explored at ward level, facilitated by the project CLO. Quarterly CAC meetings were being held as planned with $95 \%$ attendance by ward representatives recorded at each of the four meetings held between December 2003 and December 2004. Tools adapted from PLA techniques were used at ward and site-level meetings to explore project-related concerns in depth, to define priority areas for intervention and to

Deleted: from participatory learning and action (

Deleted: ) al., 2007). For example, concerns that blood specimens collected in the clinic were being sold for the purposes of witchcraft were allayed following a visit by $\underline{\mathrm{CAC}}$ members to the site laboratory where they observed how specimens were processed and residual serum saved and archived in freezers. Other issues raised through the CLS and subsequently tackled by the research team include clinic waiting times, travel allowances, range of clinical services provided, procedures for HIV testing and care and support for women found to be HIV positive. 
In a sub-study among 85 study participants from 20 randomly selected clusters conducted in July $2004,77 \%$ of women interviewed said they knew their cluster representative and had interacted with her at least once in the past to discuss a project related concern; $60 \%$ of participants had interacted with their representative in the past 4 weeks (MDP-Mwanza, 2004). These results were supported by anecdotal reports from project fieldworkers suggesting that interaction and communication between women within the same facility cluster was frequent and open,

\section{DISCUSSION}

Deleted: and

Deleted: said they

Deleted: community

Deleted: relatively regular, Deleted:

Deleted: probably because many women spend the majority of their

day at their place of work. I

Deleted: ............ Page Break............

MacQueen et al (2001) propose an evidence-based definition of community as 'a group of people with diverse characteristics who are linked by social ties, share common perspectives, and engage in joint action in geographical locations or settings' (MacQueen et al., 2001). Based on these four core constructs, 'community' could have been conceptualised in a number of ways in Mwanza For example, all women living in selected wards in the city; or all members of a specific Formatted: English U.K. occupational group. The definition of community adopted in Mwanza was conceived and articulated by the primary research stakeholders that is, women working in food and recreational facilities who perceived themselves not only as part of an occupational group, but as a discrete community with shared social ties, perspectives and experiences within a defined geographical location. Women have reported engaging in joint action at grassroots facility and cluster level (e.g. by covering work absence due to family problems, providing food and sharing resources). Feedback during CAB meetings in the on-going MDP301 trial suggest that the CLS in itself is promoting the development of shared ideals and goals at least among community representatives, where there is an appreciation that women in this community can play a vital role in the development of female-controlled HIV prevention methods and that it is possible to work in partnership with researchers towards a shared vision (Vallely, Shagi et al., 2007). 
These may not be unique outcomes in the context of HIV prevention trials, nor is a CAB based on participant representatives (a 'population-specific model') in itself new (Morin et al., 2003). What then was new or different about the approach taken in the Mwanza feasibility study and does this represent a model that could be replicated elsewhere? In Mwanza, the community, its composition, geographical location and sub-divisions, and the systems designed to represent it were all led by the community itself in a process facilitated by the research team using a variety of participatory tools. Embracing 'bottom-up' community-led ideas and the inherent opportunities of 'failing forward' within the context of community development are certainly not new (Chambers, 1997) but have not to our knowledge previously been described in the clinical trials setting. These core principles underlie our approach to community liaison in Mwanza and combined with the participatory tools described above, represent a model that can be applied in HIV prevention Deleted: als research among other vulnerable study populations.

Our approach had a number of distinct advantages. First, it demonstrated the respect which the research team had for the views, perceptions and values of study participants and a commitment to joint working and partnership. Clustering has allowed meetings to be held close to the workplace, resulting in minimal disruption to day-to-day work activities, helping to ensure on-going support from facility owners and managers. Women have been provided with an opportunity to voice opinions and to discuss concerns openly within the boundaries of their peer group at cluster meetings and locally-appropriate mechanisms for capturing and documenting key issues have been developed. Secondly, the model has facilitated direct interaction between researchers and study participants, which has helped ensure the validity of joint action plans designed to tackle key project-related concerns (Vallely, Shagi et al., 2007). Prior to the start of the main trial, feedback from the CAC was vital in determining the appropriateness of clinical procedures, mobilisation activities, referral mechanisms for STI tracing and HIV/AIDS-related care that were proposed for the trial. Third, with the start of the phase III trial in Mwanza in November 2005, the community liaison system has facilitated efficient informal two-way communication between the community and the research team. For example, it has allowed unexpected adverse events occurring in the 
community to be rapidly communicated to clinical research staff. Conversely, news of the early termination of the CONRAD and FHI cellulose sulphate microbicide trials in January 2007

(CONRAD, 2007) was discussed and disseminated through the CAC within days and valuable input provided for our broader communication strategy (e.g. due to high levels of illiteracy in the cohort, individual participants are being provided with information using audio tapes administered in the clinic using personal stereos). Fourth, an unexpected positive outcome was that over time, community representatives have increasingly felt empowered to disclose their participation in the trial and to take on an advocacy role within the broader local community. Many CAC members have deliberately worn project T-shirts to work in order to promote debate about the trial, have openly discussed their participation in MDP and overall, report receiving positive responses from the broader community. Several representatives have given interviews to the media e.g. the BBC Swahili Programme on World AIDS Day, December 2006. Finally, the cluster-based model has developed into the foundation for ward-specific mobilisation and recruitment strategies in the main trial and allowed targeted interventions to be jmplemented in several wards to tackle key issues e.g. participatory theatre was used in Nyakato to provide more jnformation about the trial to men

Given these apparent advantages, what are the Jimitations of our approach? It is very unlikely that all women in the cohort have an equal opportunity to participate in community activities or to interact with cluster representatives. Women in this occupational group are vulnerable, stigmatised within the broader community and at risk of social harm from their sexual partners (Desmond et al., 2005a; Gysels et al., 2002). Facility owners and managers are often supportive of our work but some actively discourage women from participating in community meetings or attending study clinics due to concerns that participation will be equated with HIV positive status within the broader community and that this will adversely affect business. Similarly, while some of the women's sexual partners are very supportive of their participation in the research and the community liaison activities, others are not. These contextual factors bring into question who community 'representatives' actually represent, and may affect the validity of project-related issues and concerns which they report at cluster and ward-level meetings and the joint action

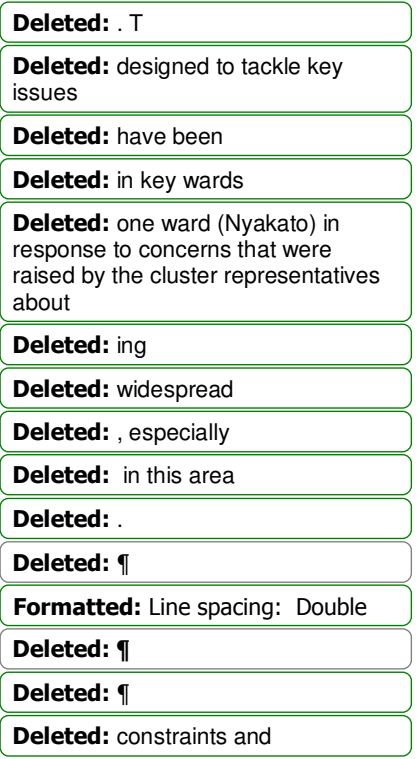

Deleted: Such differences 
plans developed at site-level workshops and CAC meetings. In the main trial we are continuing to identify and address potential constraints to participation and to monitor representation and levels of participant interaction with community representatives closely. The CLS is being expanded to ensure clusters include all 1107 facilities mapped in the ten study wards and fieldworkers have been trained to maintain up to date facility lists and ward maps. Evidence to date (July 2007) from project fieldworkers, CLO and community representatives suggests that interaction remains high with a shift towards gel-related jssues observed following the start of the trial.

Deleted: questions and

Deleted: ๆ

We believe that adopting a participatory, community-led approach during the feasibility study in Mwanza allowed us to build an effective, representative community liaison system to support the on-going phase III microbicide trial. This approach represents a model for community liaison in HIV prevention trials among vulnerable, stigmatised high-risk groups in sub-Saharan Africa and other resource limited settings.

\section{ACKNOWLEDGEMENTS}

Our special thanks go to the women of Mwanza who participated in the study and in particular to members of the Community Advisory Committee who gave invaluable advice and without whom this project would not have been possible. We thank our colleagues in the National Institute for Medical Research, Mwanza, Tanzania and the African Medical and Research Foundation, Mwanza, Tanzania for their support and assistance in carrying out this research. We also acknowledge the contribution of Sheena McCormack (Chief Investigator MDP301 Trial) and Richard Mutemwa (Community Liaison Group Coordinator), Microbicides Development Programme, Medical Research Council, London, UK.

Deleted: ๆ

COMPETING INTERESTS None declared

Deleted: ๆ

Deleted: ๆ

FUNDING_Department for International Development and the Medical Research Council, UK 


\section{REFERENCES}

Annett, H., \& Rifkin, S. B. (1995). Guidelines for Rapid Participatory Appraisals to Assess Community Health Needs. Geneva: WHO.

Baum, F., MacDougall, C., \& Smith, D. (2006). Participatory action research. Journal of Epidemiology and Community Health, 60, 854-857.

Boerma, J. T., Urassa, M., Nnko, S., Ng'weshemi, J., Isingo, R., Zaba, B., et al. (2002). Sociodemographic context of the AIDS epidemic in a rural area in Tanzania with a focus on people's mobility and marriage. Sex Transm Infect, 78 Suppl 1, i97-105.

Brown, C. S., Lloyd, S., \& Murray, S. A. (2006). Using consecutive Rapid Participatory Appraisal studies to assess, facilitate and evaluate health and social change in community settings. . BMC Public Health, 6(1), 68.

Busza, J., \& Schunter, B. T. (2001). From competition to community: participatory learning and action among young, debt-bonded Vietnamese sex workers in Cambodia. Reprod Health Matters, 9(17), 72-81.

Chambers, R. (1983). Rural Development. Putting the Last First. Harlow: Longman.

Chambers, R. (1997). Whose Reality Counts? Putting the first last. London: Intermediate Technology Publications

Clift, S., Anemona, A., Watson-Jones, D., Kanga, Z., Ndeki, L., Changalucha, J., et al. (2003). Variations of HIV and STI prevalences within communities neighbouring new goldmines in Tanzania: importance for intervention design. Sex Transm Infect, 79(4), 307-312.

CONRAD. (2007). Phase III trials of cellulose sulfate microbicide for HIV prevention closed. (Press Release ). Arlington, VA: CONRAD.

Corcega, T. F. (1992). Participatory research: getting the community involved in health development. International Nursing Review, 39(6), 185-188.

Cornwall, A., \& Jewkes, R. (1995). What is participatory research? Social Science and Medicine, 41(12), 1667-1676.

Cox, L. E., Rouff, J. R., Svendsen, K. H., Markowitz, M., \& Abrams, D. I. (1998). Community advisory boards: their role in AIDS clinical trials. Terry Beirn Community Programs for Clinical Research on AIDS. Health and Social Work, 23(4), 290-297.

Desmond, N., Allen, C. F., Clift, S., Justine, B., Mzugu, J., Plummer, M. L., et al. (2005a). A typology of groups at risk of HIV/STI in a gold mining town in north-western Tanzania. Social Science and Medicine, 60(8), 1739-1749.

Desmond, N., Allen, C. F., Clift, S., Justine, B., Mzugu, J., Plummer, M. L., et al. (2005b). A typology of groups at risk of HIV/STI in a gold mining town in north-western Tanzania. SoC Sci Med, 60(8), 1739-1749. 
Esparza, J., \& Burke, D. (2001). Epidemiological considerations in planning HIV preventive vaccine trials. AIDS, 15 (Supp 5), S49-S57.

Gysels, M., Pool, R., \& Nnalusiba, B. (2002). Women who sell sex in a Ugandan trading town: life histories, survival strategies and risk. Social Science and Medicine, 54, 179-192.

Kapiga, S., Sam, N., \& Shao, J. (2002). HIV-1 epidemic among female bar and hotel workers in northern Tanzania: risk factors and opportunities for prevention. . J Acquir Immune Defic Syndr 29(4), 409-417.

Khanlou, N., \& Peter, E. (2005). Participatory action research: considerations for ethical review. Social Science and Medicine, 60(11), 2333-2340.

Macaulay, A. C., \& Nutting, P. A. (2006). Moving the Frontiers Forward: Incorporating CommunityBased Participatory Research Into Practice-Based Research Networks. Annals of Family Medicine, 4, 4-7.

MacQueen, K. M., McLellan, E., Metzger, D. S., Kegeles, S., Strauss, R. P., Scotti, R., et al. (2001). What Is Community? An Evidence-Based Definition for Participatory Public Health. American Journal of Public Health, 91(12), 1929-1938.

Mahr, J., Wuestefeld, M., ten Haaf, J., \& Krawinkel, M. B. (2004). Nutrition education for illiterate children in southern Madagascar addressing their needs, perceptions and capabilities.

Public Health Nutrition, 8(4), 366-372.

MDP-Mwanza. (2004). Evaluation of the MWAMKO Community Liaison System: NIMR/LSHTM/AMREF Mwanza, Tanzania.

MDP. (2007). Retrieved 6 May 2007, from http://www.mdp.mrc.ac.uk/

Meyers, K., Metzger, D. S., McLellan, A. T., Navaline, H., Sheon, A. R., \& Woody, G. E. (1995). Will preventive HIV vaccine efficacy trials be possible with female injection drug users? J Acquir Immune Defic Syndr Hum Retrovirol, 10(5), 577-585.

Mgalla, Z., \& Pool, R. (1997). Sexual relationship, condom use and risk perception among female bar workers in north-west Tanzania. AIDS Care, 9(4), 407-416.

Mills, E., Nixon, S., Singh, S., Dolma, S., Nayyar, A., \& Kapoor, S. (2006). Enrolling women into HIV preventive vaccine trials: an ethical imperative but a logistical challenge. PLoS Med, 3(3), e94.

Morin, S. F., Maiorana, A., Koester, K. A., Sheon, N. M., \& Richards, T. A. (2003). Community consultation in HIV prevention research: a study of community advisory boards at 6 research sites. Journal of Acquired Immune Deficiency Syndromes, 33(4), 513-520.

Moser, D. J., Arndt, S., Kanz, J. E., Benjamin, M. L., Bayless, J. D., Reese, R. L., et al. (2004). Coercion and informed consent in research involving prisoners. Comprehensive Psychiatry, 45(1), 1-9. 
Murray, S. A. (1999). Experiences with "rapid appraisal" in primary care: involving the public in assessing health needs, orientating staff, and educating medical students. BMJ, 318, 440444.

Muruli L, Reardon O, Kisuya B, Muthui M, \& Vallely A. (2001). Participatory rural appraisal among agro-industrial communities in the sugar-belt region of Nyanza, Kenya.: Futures Group Kenya.

Nancholas, S. (1998). How to do or not to do a Logical Framework. Health Policy and Planning, 13(2), 189-193.

NIMH. (2007). Design and integration of ethnography within an international behavior change HIV/sexually transmitted disease prevention trial. AIDS, 21 Supp/ 2, S37-48.

Nkya, W., Gillespie, S., \& Howlett, W. (1991). Sexually transmitted diseases in prostitutes in Moshi and Arusha, Northern Tanzania. Int J STD AIDS 2(6), 432-435.

Nyamathi A, Koniak-Griffin D, Tallen L, Gonzalez-Figueroa E, Levson L, Mosley Y, et al. (2004). Use of community-based participatory research in preparing low income and homeless minority populations for future HIV vaccines. Journal of Interprofessional Care, 18(4), 369380.

Ong, B. N., Humphris, G., Annett, H., \& Rifkin, S. (1991). Rapid appraisal in an urban setting, an example from the developed world. Soc Sci Med., 32(8), 909-915.

Page-Shafer, K., Saphonn, V., Penh Sun, L., Chhi Vun, M., Cooper, D. A., \& Kaldor, J. M. (2005). HIV prevention research in a resource-limited setting: the experience of planning a trial in Cambodia. Lancet, 366, 1499-1503.

Sherr, L., Bolding, G., \& Elford, J. (2004). Recruiting London gay men into an HIV vaccine trial: Is it feasible? AIDS Care, 16(5), 565-571.

Suligoi, B., Wagner, T. M., Ciccozzi, M., \& Rezza, G. (2005). The epidemiological contribution to the preparation of field trials for HIV and STI vaccines: objectives and methods of feasibility studies. Vaccine, 23(12), 1437-1445.

UNAIDS. (2007). Good participatory practice guidelines for biomedical HIV prevention trials. Geneva: Joint United Nations Programme on HIV/AIDS (UNAIDS) 2007.

Vallely A, Scott C, \& Hallums J. (1999). The Health Needs of Refugees: Using rapid appraisal to assess needs and identify priority areas for public health action. Public Health Medicine, 1(3), 103-107.

Vallely, A., Kasindi, S., Hambleton, I. R., Knight, L., Chirwa, T., Balira, R., et al. (2007). Microbicides Development Programme, Tanzania. Baseline characteristics of an occupational cohort and re-attendance at three months. Sexually Transmitted Diseases, 34(9), 638-643. 
Vallely, A., Shagi, C., Kasindi, S., Desmond, N., Lees, S., Chiduo, B., et al. (2007). The benefits of participatory methodologies to develop effective community dialogue in the context of a microbicide trial feasibility study in Mwanza, Tanzania. BMC Public Health, 7, 133.

Wright, J., \& Walley, J. (1998). Assessing health needs in developing countries. BMJ, 316, 18191823. 
Figure 1: Logical framework, Community Liaison System, Mwanza

\begin{tabular}{|c|c|c|c|}
\hline Narrative & Indicators & Means of verification & Assumptions \\
\hline \multicolumn{4}{|c|}{$\begin{array}{l}\text { GOAL } \\
\text { To conduct a successful clinical trial of vaginal microbicides in partnership with the community }\end{array}$} \\
\hline $\begin{array}{l}\text { OUTPUTS } \\
\text { 1. Effective community } \\
\text { liaison system (CLS) for } \\
\text { women in the MDP Mwanza } \\
\text { cohort established in } 10 \\
\text { wards in Mwanza City }\end{array}$ & $\begin{array}{l}\text { By Dec } 03 \\
\text { 1.1. } 90 \% \text { of cluster reps attend and } \\
\text { actively participate in monthly } \\
\text { ward-level meetings } \\
\text { 1.2. } 90 \% \text { of ward reps attend and } \\
\text { actively participate in quarterly } \\
\text { site-level meetings ('Community } \\
\text { Advisory Board') } \\
\text { 1.3. } 80 \% \text { of randomly selected study } \\
\text { participants can identify their } \\
\text { cluster reps and feel they could } \\
\text { approach her with project-related } \\
\text { concerns } \\
\text { 1.4. } 90 \% \text { of key concerns raised } \\
\text { through CLS are addressed by } \\
\text { project in a timely and } \\
\text { appropriate manner }\end{array}$ & $\begin{array}{l}\text { 1.1. CLO monthly reports } \\
\text { 1.2. CLO monthly reports } \\
\text { 1.3. Quarterly small-scale } \\
\text { surveys } \\
\text { 1.4. Minutes of site-level } \\
\text { meetings; minutes and } \\
\text { presentations at quarterly } \\
\text { MWAMKO management } \\
\text { meetings }\end{array}$ & $\begin{array}{l}\text { Representatives at } \\
\text { cluster, ward and site } \\
\text { level truly represent the } \\
\text { views and concerns of } \\
\text { women in the study } \\
\text { cohort }\end{array}$ \\
\hline $\begin{array}{l}\text { 2. Ward, community leaders } \\
\text { and other stakeholders } \\
\text { support the project }\end{array}$ & $\begin{array}{l}2.1 \text { No negative reaction to the project } \\
\text { detected among stakeholders at any } \\
\text { level }\end{array}$ & $\begin{array}{l}\text { 2.1. Minutes of City HIV/AIDS } \\
\text { Management Committee } \\
\text { meetings; informal feedback } \\
\text { from key stakeholders }\end{array}$ & $\begin{array}{l}\text { Changes in local } \\
\text { administration proceed } \\
\text { smoothly }\end{array}$ \\
\hline
\end{tabular}




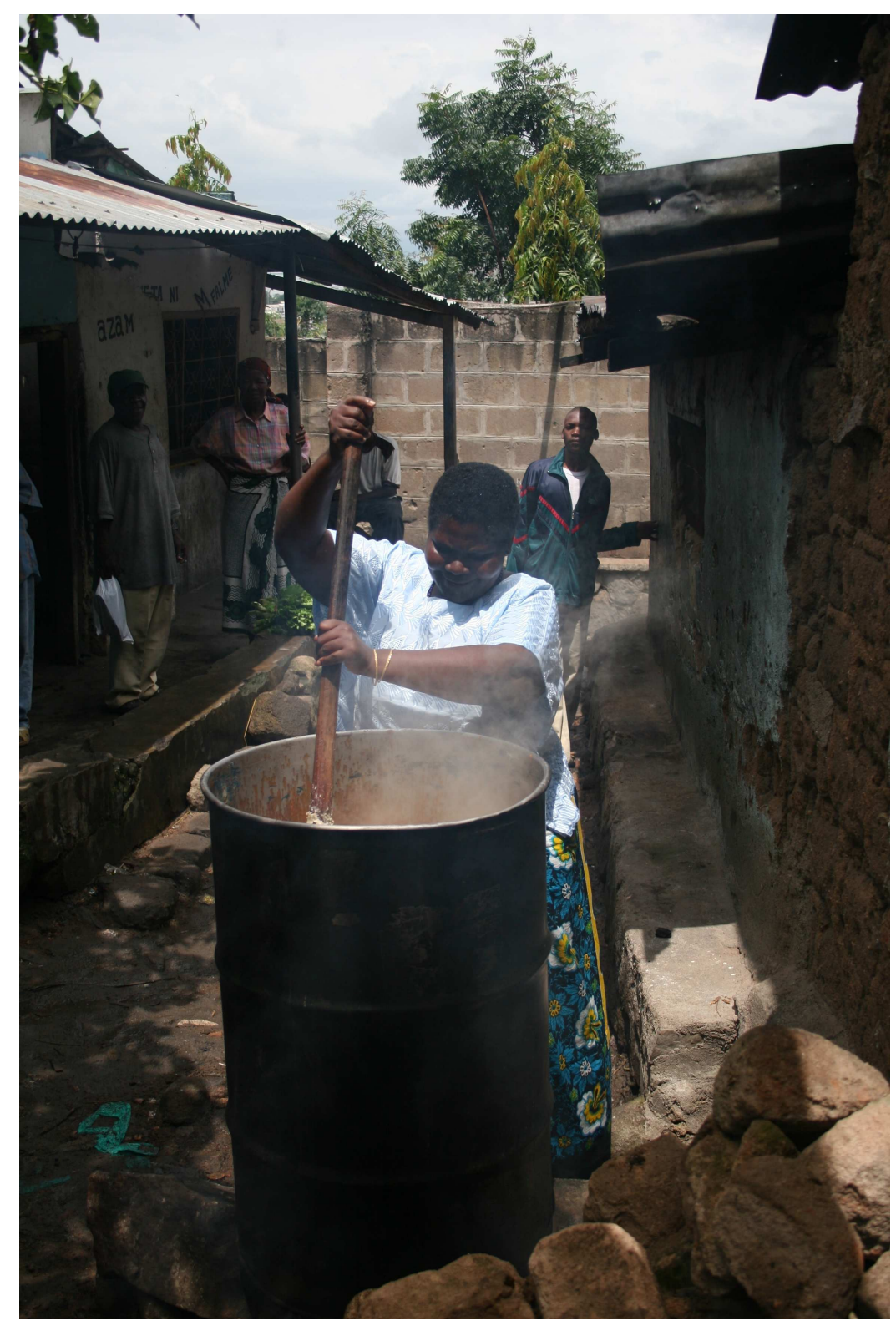

Making locally-brewed beer outside a traditional bar or kilabu, Mwanza $824 \times 1236 \mathrm{~mm}(72 \times 72$ DPI $)$ 


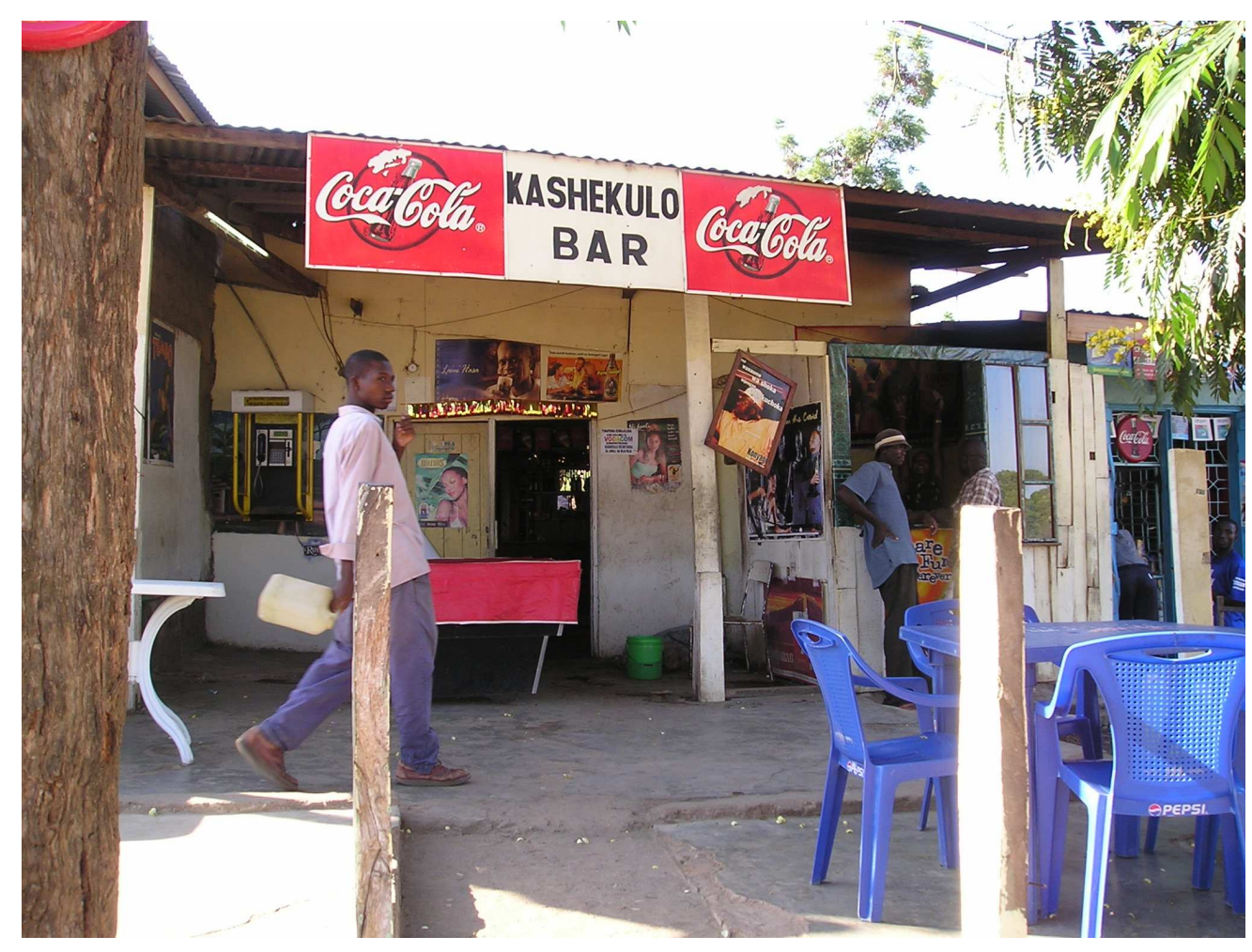

Modern bar, Mkuyuni ward, Mwanza $722 \times 541 \mathrm{~mm}(72 \times 72 \mathrm{DPI})$ 
Figure 4: Facility cluster types

\begin{tabular}{|c|c|c|}
\hline Cluster type & $\begin{array}{l}\text { Characteristic features } \\
\text { of facilities within the cluster }\end{array}$ & $\begin{array}{l}\text { Characteristics of women working at } \\
\text { facilities }\end{array}$ \\
\hline $\begin{array}{l}\text { Type-A: } \\
\text { Mamalishe / kilabu } \\
\text { (traditional bar) }\end{array}$ & $\begin{array}{l}\text { low-income self-employed businesses; } \\
\text { open air, makeshift, temporary structure } \\
\text { (e.g. bamboo walls, packed mud floor, } \\
\text { grass thatch roof) } \\
\text { facilities typically owned and managed by } \\
\text { women } \\
\text { generally located away from main streets } \\
\text { in economically deprived areas }\end{array}$ & $\begin{array}{l}\text { - older women with 'traditional' } \\
\text { appearance (e.g. wear long dress, } \\
\text { headscarf, khanga) } \\
\text { - younger women working at the facility } \\
\text { tend to be relatives and receive little or } \\
\text { no pay }\end{array}$ \\
\hline $\begin{array}{l}\text { Type-B: } \\
\text { Modern bar / hotel / } \\
\text { guesthouse / } \\
\text { restaurant / other }\end{array}$ & $\begin{array}{l}\text { - established businesses able to pay salary } \\
\text { to staff located in a permanent building } \\
\text { (e.g. cement or brick construction; iron or } \\
\text { tiled roof) } \\
\text { - typically owned by men; women employed } \\
\text { as barmaids, waitresses, cleaners, } \\
\text { receptionists and in food preparation } \\
\text { - generally situated in the more affluent } \\
\text { areas. }\end{array}$ & $\begin{array}{l}\text { younger women with more Western } \\
\text { appearance (e.g. wear jeans, T-shirt) }\end{array}$ \\
\hline
\end{tabular}




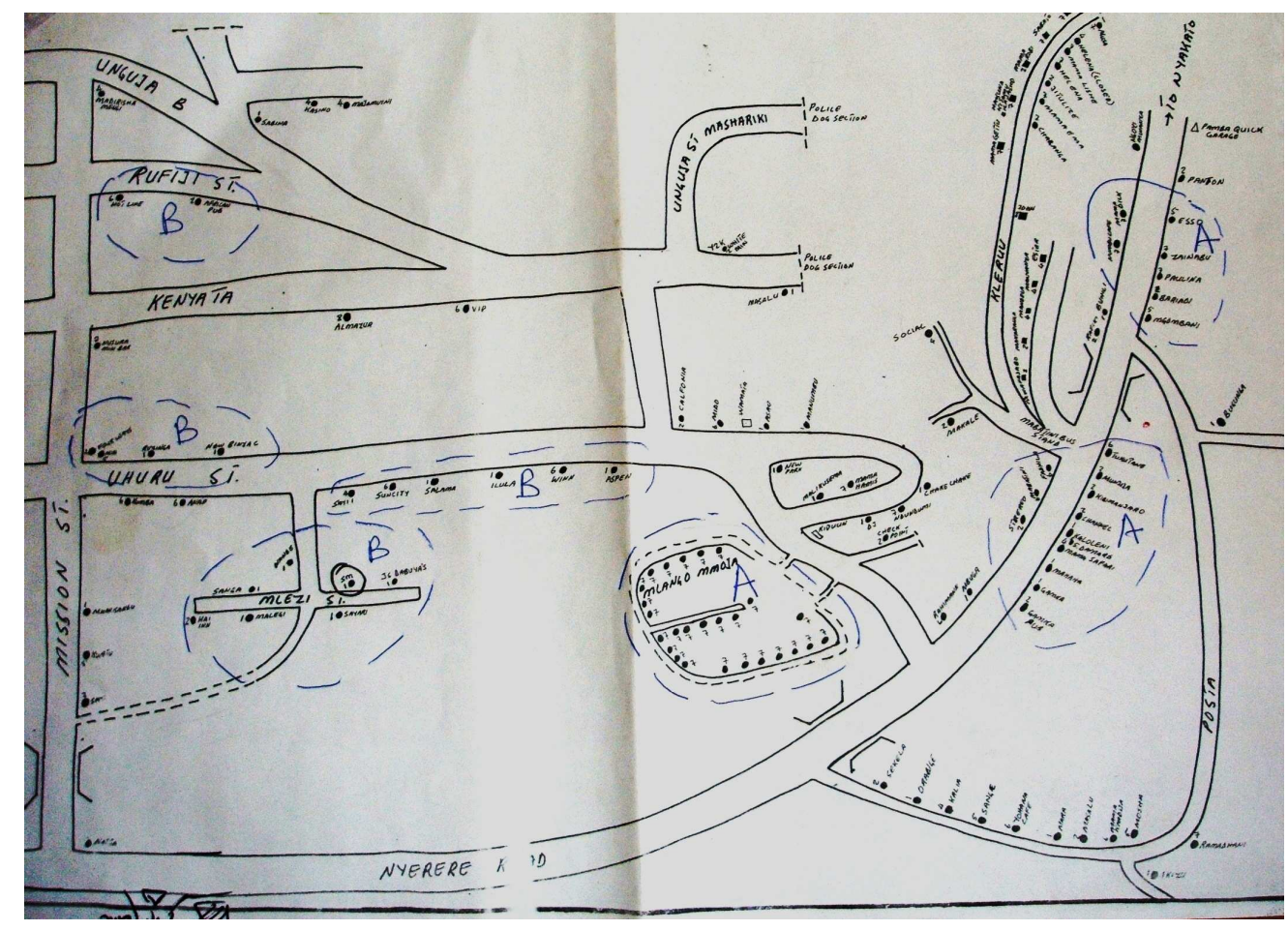

Ward map showing facility cluster types $762 \times 548 \mathrm{~mm}$ (72 x 72 DPI) 